\title{
Determining an effective and coherent theoretical basis for the validity of consent in clinical trials
}

\author{
Puneet Arora ${ }^{1,2 *}$ \\ ${ }^{1}$ Departments of Open Learning, Thompson Rivers University, Kamloops, BC, Canada \\ ${ }^{2}$ Department of Community and Health Studies, Mount Royal University. Calgary, AB, Canada
}

\begin{abstract}
Informed consent is one of the most important aspect of any clinical trial study and its related ethical concerns. It forms one of the most pivotal legal requirements for conducting clinical trials involving humans. There have been difficulties in establishing an operational and coherent theoretical basis for the validity of consent in clinical trials. Although difficult to determine, yet can be understood through some well-established principles and procedures involved in clinical trials. This article will review some concepts and vitality of "consent" in the medical practice while touching base with the historical perspective of informed consent. The main focus of the article will revolve around validity and theoretical basis of informed consent in clinical trials while taking into consideration several rules, regulations, legislations and case laws forming the basis for argumentation.
\end{abstract}

\section{Introduction}

Clinical trial is "the most definitive tool for evaluation of the applicability of clinical research." In fact, it is widely believed that properly conducted clinical trials that follow the scientific experimentation principles provide "the only reliable basis for evaluating the efficacy and safety of new treatments." ${ }^{2}$ However, with the involvement of humans in the clinical trials, questions have been asked about the ethics involved in such trials. Informed consent of the human subjects participating in the research is an important ethical consideration that requires thorough deliberation. The theoretical basis for the validity of such consent, although difficult to ascertain, yet can be understood through some well-established principles and procedures of clinical trials.

In order to develop cogent and lucid reasoning for the arguments, the author has divided this article into three segments. The author commence by introducing the concept and vitality of "consent" in the medical practice. The second segment presents a brief historical perspective on the origination of the idea of informed consent among adults participating in the clinical trials. The third segment is the operating part of this article in which the validity of informed consent is explored. This segment takes a closer look at the concept of informed consent and drives home the point that despite the controversy over the desirability of informed consent in clinical trials, there cannot be any substitute to full autonomy in such matters and in which, informed consent in an indispensable cog in the wheel. Several rules, regulations, legislations and case laws form the basis for argumentation.

The author has restricted the research to the US and UK jurisdictions - the former being the most proactive in terms making it a legal requirement to obtain a written informed consent for every patient entering a clinical trial, and the later relying on local ethical

${ }^{1}$ Friedman L.M., Furberg C.D., DeMets D., Fundamentals of Clinical Trials $\left(4^{\text {th }}\right.$ Edn., Springer: 2010), Preface vii.

${ }^{2}$ Pocock S.J., Clinical Trials: A Practical Approach (John Wiley \& Sons, 1983), at 1. committees for deciding whether written informed consent should be obtained from the subject for a particular research or an implied and verbal consent are acceptable. ${ }^{3}$ The rules and practices relating to informed consent followed in the US are the trendsetters for other countries, including the UK. However, as Pocock pointed out that all countries should not be encouraged to adopt the American approach for written informed consent because of two reasons - one, "it would be an unrealistic and undesirable uniformity of practice" and two, "such an approach is partly motivated by the need to protect doctors from subsequent litigation if trial therapy is not successful." 4

\section{Consent}

Generally, consent is of three types: express; ${ }^{5}$ implied in fact; ${ }^{6}$ and implied in law. ${ }^{7}$ Recent developments indicate a fourth type of consent that is accepted among medical fraternity, i.e., informed consent, which was acknowledged by the court in Bang $v$ Charles T. Miller Hospital

\section{${ }^{3}$ Ibid., at 106}

${ }^{4}$ Ibid., at 106

${ }^{5}$ See, Farber v Olkon 40 C.2d 503; 254 P.2d 520 (1953), wherein it was held that if an adult child is incompetent and has no legally appointed guardian, the right to consent to emergency treatment resides in the parent who has the legal responsibility to maintain such child.

${ }^{6}$ See, McGuire v Rix, 118 Neb. 434, 225 N.W. 120 (1929), wherein the court said, “... consent may be implied from circumstances and an operation may be demanded by an emergency without consent."

${ }^{7}$ See, Luka v Lowrie 171 Mich. 122, 136 N.W. 1106 (1912), wherein the court held that in case the emergency endangered the life of the patient if not treated immediately and the time needed to reach the parents made it 'impractical' to obtain their consent, then as a matter of law, consent was not needed.

${ }^{8} 251$ Minn. 427, 88 N. W. 2d 186 (1958)

${ }^{*}$ Correspondence to: Puneet Arora, Departments of Open Learning, Thompson Rivers University, Kamloops, BC, Canada, Tel: Phone: (+1) 778-231-6383; E-mail: arorapuneet@live.com

Received: May 14, 2018; Accepted: May 24, 2018; Published: May 28, 2018 
in the following words [1]: "where a surgeon can ascertain alternative situations in advance of an operation, and no immediate emergency exists, a patient should be informed of the alternate possibilities and be given a chance to decide before the doctor proceeds with the operation."

The vitality of informed consent was aptly brought out by Oppenheim in the following words: "To be legally valid, the consent given to a procedure must be intelligent, or informed consent, with an understanding of what is to be done and the risks involved." 10

The judiciary, as well as the legislature, over the years, across the globe have realised the importance of informed consent in both patient treatment and human research and experimentation. For the sake of relevance to the problem profile, this study confines itself to the idea of informed consent among adults participating in clinical trials.

\section{Historical Perspective}

The earliest traces of government regulation in clinical research and experimentation was by the Prussian Minister of the Interior in 1891, when he issued a directive to all prisons that tuberculin for the treatment of tuberculosis "must in no case be used against the patient's will."11 However, ethics in medical research on human beings first attracted limelight during the Nazi period, when hundreds and thousands of prisoners were exposed to dangerous practices of experimentation and research by the Nazis in the concentration camps. Typically, the subjects were forced to act as cultures for typhus and malaria so that once infected, they could be used to test vaccines.

Post-World War II, the world saw a historical trial (known as "Nuremberg Trial"), which delivered its verdict on August 20, 1947, wherein, 23 doctors were convicted for human experimentation in concentration camps involving 3,500,000 sterilization of German citizens. This incident was the trigger for the adoption of an international code of medical ethics, known as 'Nuremberg Code' (the "Code") [2], which inter alia, contains 10 standards of ethics that physicians must conform when carrying out experiments on human subjects. The first principle relates to "voluntary consent" and mandates that the "person involved should have legal capacity to give consent; should be so situated as to be able to exercise free power of choice, without the intervention of any element of force, fraud, deceit, duress, overreaching, or other ulterior form of constraint or coercion; and should have sufficient knowledge and comprehension of the elements of the subject matter involved as to enable him to make an understanding and enlightened decision." 12

Thus, to constitute informed consent under "Nuremberg Code", the initiator of the medical experiment must inform the subject about the nature, duration and purpose of the experiment; the method and means by which it is to be conducted; all inconveniences and hazards reasonably to be expected; the effects upon the health or person of the subject. ${ }^{13}$

Informed consent of the subjects in human experimentation and research can also be derived from Article 7 of the Universal Declaration of Human Rights, adopted by the General Assembly of the United

${ }^{9}$ Ibid. Also see, Natanson v Kline 186 Kan. 393, 350 P. 2d 1093 (1960).

${ }^{10}$ Oppenheim M., Informed Consent to Medical Treatment, 11 Clev.-Marshall L. Rev. 249 1962, at 264 .

${ }^{11}$ Official Regulations as to Tuberculin in Germany and Italy, JAMA 1891;16:492.

${ }^{12}$ Vollmaan J, Winau R., Informed Consent in Human Experimentation, Before the Nuremberg Code, BMJ 1996;313:1445-7, at 1448.

${ }^{13} \mathrm{Ibid}$.
Nations in 1948. Accordingly, "No one shall be subjected to torture or to cruel, inhuman or degrading treatment or punishment. In particular, no one shall be subjected without his free consent to medical or scientific experimentation." ${ }^{14}$

Nuremberg Code was followed by the Declaration of Helsinki in $1964[3],{ }^{15}$ which was drafted at the Eighteenth General Assembly of the World Medical Council, and which replaced a set of principles that were adopted at the Eighth Assembly in 1954. The Declaration of Helsinki has undergone multiple revisions, most recently in October 2013. Similar to Nuremberg Code, the Declaration of Helsinki also gives primacy to the informed consent of the subjects, albeit in a milder form in that in case of legal incompetence, informed consent should be obtained from the legal guardian in accordance with the national legislation.

Thus, to constitute informed consent under the Declaration of Helsinki, the physician should obtain it in writing and inform the subject about "the aims, methods, anticipated benefits and potential hazards of the study and the discomfort it may entail...he or she is at liberty to abstain from the participation in the study...he or she is free to withdraw his or her consent to participation at any time."16

Another notable development in the field of medical ethics took place in 1982 with the publishing of International Ethical Guidelines for Biomedical Research Involving Human Subjects by the World Health Association and the Council for International Organisations of Medical Sciences (CIOMS), which were later amended in 1993 and 2002. Guideline 4, inter alia, states that "for all biomedical research involving humans, the investigator must obtain the voluntary informed consent of the prospective subject or, in the case of an individual who is not capable of giving informed consent, the permission of a legally authorised representative in accordance with applicable law. Waiver of informed consent is to be regarded as uncommon and exceptional, and must in all cases be approved by an ethical review committee."17

Thus, to constitute informed consent under the International Ethical Guidelines for Biomedical Research Involving Human Subjects, the investigator must provide the following information to the individual:

i. the reasons to invite the individual for the research;

ii. individual is free to refuse to, or withdraw at any time from, participation in the research;

iii. purpose of research;

iv. procedures to be carried by the investigator;

v. explain how the research differs from routine medical care;

vi. expected duration of individual's participation in the research;

vii. whether any monetary or non-monetary benefit will be provided to the subject;

\footnotetext{
${ }^{14}$ Article 7, The Universal Declaration of Human Rights, 1948.

${ }^{15}$ Also referred to as "Recommendations Guiding Physicians in Biomedical Research Involving Human Subjects."

${ }^{16}$ In case the physician obtaining informed consent is in a dependent relationship to the subject or the consent is given under duress, the informed consent should be obtained by another physician who is not engaged in the investigation and who is completely independent of this official relationship.

${ }^{17}$ International Ethical Guidelines for Biomedical Research Involving Human Subjects, CIOMS, available at http://www.cioms.ch/publications/layout_guide2002.pdf, accessed on April 25, 2016, at 32 .
} 
viii. after completion of the research, individual will be informed of any finding that relates to his or her health status;

ix. right of individual to access his or her own data on demand;

x. any foreseeable risk or discomfort to the individual;

xi. any direct benefits resulting to the individuals participating in the research, to community or society at large;

xii. ensuring privacy and confidentiality of the individual's data, etc.

The last major international development of note in this field was the publishing of Guidelines for Good Clinical Practice by the International Conference on Harmonisation of Technical Requirements for Registration of Pharmaceuticals for Human Use (ICH) in 1996 and amended in 2002 by the European Medicines Agency. These Guidelines endorsed the ethical standards of practice as adopted in the Declaration of Helsinki.

An overview of the historical documents pertaining to informed consent involving human subjects in medical research and experimentation reveals that the ethical and regulatory norm remains that of getting free, uncoerced, informed consent of a prospective subject before that person experiences any research-related risk.

\section{Validity of Informed Consent}

The genesis of doctrine of informed consent can be traced to the case of Mohr $v$ Williams, ${ }^{18}[4]$ wherein a physician had obtained consent to operate on one ear, but after the patient had been anaesthetised, the doctor re-examined her and decided to operate on the other ear. Although his decision was medically sound and the operation was successful, the doctor was found in the wrong by the court, which observed, "if the operation was performed without plaintiff's consent, and the circumstances were not such as to justify its performance without, it was wrongful; and if it was wrongful, it was unlawful."

Although Mohr judgement was in a different context and was followed subsequently by several courts, ${ }^{19}$ yet the spirit cannot be ignored and it can be inferred that informed consent is sine qua non when the doctors, researchers, and investigators are dealing with any human, either as a patient or as a subject. ${ }^{20}$

The basis of informed consent rests on the premise that research may not be performed unless the investigator has obtained the legally effective informed consent of the subject or the subject's legally authorised representative. ${ }^{21}$ The underlying justification for informed consent is two-fold, viz., it ensures freedom of choice; and it guarantees individual's autonomy. Other aims of informed consent include bodily integrity, elevation of rational decision-making, prevention of fraud and duress, promotion of self-scrutiny by the physician-investigator, and involvement of the public in significant issues of health care research and policy. ${ }^{22}$ As Dan Brock puts it, 'the rule that, with a

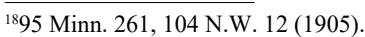

${ }^{19}$ See, e.g., Schloendorff v New York Hospital 211 N.Y. 125 (1914), wherein Judge Benjamin Cardozo remarked: "[e]very human being of adult years and sound mind has a right to determine what shall be done to his body."

${ }^{20}$ Also see, Salgo v Stanford University 154 Cal. App. 2d 560, 317 P.2d 170 (1957), wherein the court held that "uninformed consent to medical treatment is not true consent, and thus, a physician must disclose all information necessary for the patient to make informed health care decisions."

${ }^{21} 45$ C.F.R. $\$ 46.116$ Code of Federal Regulations Title 45 Public Welfare Department of Health and Human Services Part 46 Protection of Human Subject.

${ }^{22}$ Quittell, R. M., Informed Consent and Human Experimentation: Present Status, Pitfalls, and the Need for Reform, (2001 Third Year Paper), Food and Drug Law, 2001. few exceptions, research with humans should not take place without participants' informed consent is a settled ethical and legal principle. ${ }^{23}$

\section{What Constitutes Informed Consent?}

Several international instruments, as discussed hereinabove, have defined "informed consent" differently. However, a common thread among all these definitions runs seamlessly, i.e., the subject must be communicated all the essential details about the research and experiment that he or she is proposed to be a part of.

The Code of Federal Regulations issued by the U.S. Public Welfare Department of Health and Human Services minutely details the information that should be communicated to the subject in order to constitute informed consent. Accordingly, informed consent includes:

i. A statement mentioning that the study involves research;

ii. An explanation of the purposes of the research; The expected duration of the subject's participation;

iii. A description of the procedures to be followed;

iv. Identification of any experimental procedures (if applicable);

v. A description of any reasonably foreseeable risks or discomforts to the subject;

vi. A description of any benefits to the subject or to others, which may reasonably be expected from the research;

vii. A disclosure of appropriate alternative procedures or courses of treatment, if any, that might be advantageous to the subject;

viii. A statement describing the extent, if any, to which confidentiality of records identifying the subject will be maintained;

ix. For research involving more than minimal risk, an explanation as to whether any compensation and an explanation as to whether any medical treatments are available if injury occurs and, if so, what they consist of, or where further information may be obtained; An explanation of whom to contact for answers to pertinent questions about the research and research subjects' rights, and whom to contact in the event of a research-related injury to the subject; and

x. A statement that participation is voluntary, refusal to participate will involve no penalty or loss of benefits to which the subject is otherwise entitled to, and the subject may discontinue participation at any time without penalty or loss of benefits to which the subject is otherwise entitled. ${ }^{24}$

Other than the above mentioned basic elements that constitute informed consent, there are certain additional elements, which may or may not be applicable to all the researches, including:

A statement that the particular treatment or procedure may involve risks to the subject (or to the embryo or foetus, if the subject is or may become pregnant), which are currently unforeseeable; Anticipated circumstances under which the subject's participation may be terminated by the investigator without regard to the subject's consent; Any additional costs to the subject that may result from participation in the research; The consequences of a subject's decision to withdraw from the research and procedures for orderly termination of participation by the subject; A statement that significant new findings developed during the course of the research which may relate to the subject's willingness ${ }^{23}$ Brock, D.W., Philosophical Justifications of Informed Consent in Research, in The
Oxford Textbook of Clinical Research Ethics 606 (Ezekiel Emanuel et al. eds., 2008).

${ }^{24}$ Code of Federal Regulations, supra, note 21. 
to continue participation will be provided to the subject; and The approximate number of subjects involved in the study..$^{25}$

\section{The Controversy}

Autonomy, in the matters of medical research, even though a cherished objective, has generated a lot of controversy as well. The general assumption is that research is ethical only if it satisfies several additional ethical criteria other than the requirement of informed consent. For instance, whether the research has any social value, whether the design of the research will yield any scientifically valid data and, whether the risks to subjects are reasonable in relation to the anticipated benefits to subjects or to others. ${ }^{26}$

There may be certain technical aspects that need to be communicated to the subject in order to complete the informed consent. However, the subject may not be in a position to comprehend what is being communicated to him or her. As Evans and Evans put it, "Not only can one never be quite sure of the success of the venture of informing a research subject and allowing a voluntary decision to be made, it remains true that there are some things, which it is simply not right to ask people to do in the name of research., ${ }^{27}$

Wertheimer contends that informed consent is not strictly necessary for ethical research in that consent may not be required when the research it is exclusively observational. ${ }^{28}$ Piff sought to explain the situation by drawing an analogy with wealthy driver by posing a question as to whether wealthy drivers behaved more unethically than less wealthy drivers if the drivers of expensive cars were more likely to cut off other vehicles at an intersection..$^{29}$ Another common practice among researchers, especially interventional researchers, is that informed consent may be dispensed with when subjects must be deceived if research is to produce scientifically valid data. ${ }^{30}$

Moreover, the Code of Federal Regulations also admit a number of exceptions to the doctrine of informed consent, viz., when research involves only minimal risk to the subjects; when waiver or alteration will not adversely affect the rights and welfare of the subjects; when the research could not practicably be carried out without the waiver or alteration; whenever appropriate, the subjects will be provided with additional pertinent information after participation; and when the research could not practicably be carried out without the waiver or alteration of requirement of informed consent. ${ }^{31}$

Besides, there are other roadblocks in the way of informed consent, e.g., language barrier, ${ }^{32}$ religious influence, ${ }^{33}$ and false expectations

\section{${ }^{25}$ Ibid.}

${ }^{26}$ Emanuel E.J., Wendler D. \& Grady C., What Makes Clinical Research Ethical?, 283 JAMA 2701 (2000)

${ }^{27}$ Evans D. and Evans M., A Decent Proposal: Ethical Review of Clinical Research, John Wiley and Sons, 1996.

${ }^{28}$ Wertheimer A., (Why) Should We Require Consent to Participation in Research?, J Law Biosci (June 2014) 1 (2): 137-182.

${ }^{29}$ Piff P., et al., Higher Social Class Predicts Increased Unethical Behavior, 109 Proc Natl Acad Sci USA 4086 (2012). DOI: 10.1073/pnas.1118373109.

${ }^{30}$ See Dan Ariely, The Honest Truth about Dishonesty: How We Lie To Everyone-Especially Ourselves (2012).

${ }^{31}$ Code of Federal Regulations, supra, note 21.

${ }^{32}$ For example, patients who did not speak the same language as their doctors had a greater tendency to skip their medication and to miss their appointments than patients who shared a common language with their doctors. See, Baker, D.W., Hayes, R., \& Fortier, J.P., Interpreter use and satisfaction with inter-personal aspects of care for Spanish-speaking patients, Med Care 1998; 36:1461-1470.

${ }^{33}$ For example, Jehovah Witnesses are not allowed to receive any blood transfusions and organ transplants of any kind. See, Pimentel Perez, A.G., Los testigos de Jehova y el consentimiento informado, Revista de Medicina, Instituto Mexicano del Seguro Social (IMSS). 2002; 40(6): 495-504. from the research and experimentation.

Therefore, it is often contended that there are difficulties in ascertaining an effective and coherent theoretical basis for the validity of consent in adults participating in clinical trials.

\section{The Rebuttal}

Informed consent has been central to any research activity involving humans. In fact, it is viewed by some as the principal component of the desired trust levels, which must accompany any research venture. So much so that the failure to obtain consent has been the basis for claims of unethical research in several dubious research projects. For instance, the notorious Tuskegee Syphilis Experiment, in which around 600 impoverished Afro-American men who were part of a research that studied the natural progression of untreated syphilis were not informed about the cessation of funding to the research; thereby, exposing them to non-treatment of disease in case they had the disease. Moreover, none of the men were ever told that they had syphilis or were treated by penicillin even after it was proved that penicillin was effective in the treatment of syphilis. Resultantly, numerous men died of syphilis.

The centrality of informed consent from competent adults or adequately represented individuals in clinical trials was amply brought out by McHale et al: "The concept of consent operates as a unifying principle running through health care law. It represents the legal and ethical expression of the human right to have one's autonomy and selfdetermination respected." ${ }^{34}$

Further, the requirement that the patient's consent is to be obtained also operates as a constraint on the power of healthcare professionals. ${ }^{35}$

In order to reconcile both ends, i.e., difficulty in arriving at a theoretical basis for the validity of consent in adults participating in clinical trials, and the desirability of informed consent among the adult and competent subjects in medical trials as part of autonomy and bodily integrity, it is important to contrast therapeutic and nontherapeutic procedures.

In non-therapeutic procedures, there is not much controversy, as people generally volunteer to be a part of such clinical trials out of choice. However, the problem arises in therapeutic procedures, where there are chances that volunteers agree to be a part of the clinical trials out of sheer desperation of their disease.

It has to be understood that informed consent cannot be ironclad, and that it affords certain exceptions. Although it may seem difficult on paper to arrive at a theoretical basis for informed consent, yet if we can sift out the possibilities of dispensing with the strict informed consent, and replacing it with qualified consent in such cases, the cherished objective of informed consent will not seem distant. As Jackson puts it, "there is no requirement in English law that every possible complication and side-effect should be explained to the patient." ${ }^{36}$ Similar sentiments were express by the court in Sidaway v Governors of Bethlem Royal Hospital[5]. ${ }^{37}$ In this case, it was held that "what degree of disclosure of risk is appropriate to allow the patient to make an informed choice is primarily a matter of clinical judgement."

In the same vein, Hall J., in Halushka v University of Saskatchewan $[6],{ }^{38}$ observed, "the subject of medical experimentation is entitled to

\footnotetext{
${ }^{34} \mathrm{McHale}$ J, Guidelines for Medical Research - Some Ethical and Legal Problems, (1993) 1 Medical Law Review 160-185.

${ }^{35}$ Ibid.

${ }^{36}$ Jackson, J. (ed.) A Practical Guide to Medicine and the Law, Springer- Verlag, 1991 at 20.

${ }^{37}[1985]$ AC 871

${ }^{38}(1965) 53$ D.L.R. (2d) 436
} 
a full and frank disclosure of all the facts, probabilities and opinions, which a reasonable man might be expected to consider before giving his consent."

Tobias and Souhami argue that "a distraught patient, possibly within days of diagnosis of a potentially lethal illness, may be unable to take in any but the most basic details." ${ }^{39}$ They voiced for an informed consent procedure that is humane for the patient, and not for the study as a whole. ${ }^{40}$

\section{Moving Forward}

Informed consent, although difficult to achieve in clinical trials, is still a requirement that cannot be dispensed with. If the researchers and investigators want minimum restrictions and regulations in their work, the patients and subjects have a natural right to know what and why they will be subjected to. Despite the existence of barriers, informed consent can still be achieved by the adoption of certain measures, viz.:

(i) Cultural and Linguistic Barriers: Sometimes, the consent form is drafted in a language that the subject cannot comprehend. However, by anticipating the language proficiency of the participant, the researchers can easily overcome the linguistic barrier. This can be achieved by analysing the ethnic composition of the region where the research is conducted. ${ }^{41}$ Another mode of dealing with language barrier is to have professional interpreters and translators who can explain the research and experimentation to the subjects in their own language. Escobedo et al suggested another unique method of improving the process of informed consent, i.e., to test the efficacy of the entire process by conducting a small quiz that focus on important aspects of research project, like its methodology, purpose, risks, and benefits. ${ }^{42}$ Moreover, the researchers need to be sensitive about the diverse cultural beliefs of the participants by avoiding "making assumptions about what a person believes or values based on a presumed community identity." ${ }^{43}$

(ii) Age Barrier: Minor subjects are considered unable to consent. Although not desirable, yet minors are crucial to research in so far as specific diseases are concerned (e.g., Kawasaki's Disease, Leukaemia). As regards medical treatment, Section 8 of the Family Law Reform Act 1969 provides that individuals of 16 years of age and above shall be presumed to be capable of making decisions relating to medical treatment, while those below 16 years of age shall be governed by the rule laid down in Gillick $v$ West Norfolk and Wisbech Area Health Authority ${ }^{44}$ (a.k.a. Gillick Competence) [7]. Accordingly, "As a matter of Law, the parental right to determine whether or not their minor child below the age of sixteen will have medical treatment terminates if and when the child achieves sufficient understanding and intelligence to understand fully what is proposed." The researchers should follow the basic rule that if the consent cannot be given, medical procedures are generally only able to be administered where they are in the best interests of the minor. However, the Gillick Competence does not hold ground when faced with a situation wherein a competent child refuses to be involved in a therapeutic research. Lord Donaldson M.R., in the

${ }^{39}$ Tobias, J.S. and Souhami, R.L., Fully Informed Consent Can Be Needlessly Cruel, BMY 1993;307: 1199-201, at 1200 .

${ }^{40}$ Ibid., at 1201 .

${ }^{41}$ Escobedo C., Guerrero J., Lujan G., Ramirez A., and Serrano D., Ethical Issues with Informed Consent, E-Zine Journal: Youth Scientists and the Ethics of Current Science BioEthics Issue 1, Fall 2007.

${ }^{42}$ Ibid.

${ }^{43}$ Marshall P.A., "Cultural Competence" and Informed Consent in International Health Research, Cambridge Quarterly of Healthcare Ethics (2008), 17, 206-215.

${ }^{44}[1985]$ (1985) 3 All ER 402 case of Re W (Child in Care: Court's Jurisdiction) ${ }^{45}$ [8] held that "No minor of whatever age has power by refusing to consent to treatment to override a consent to treatment by someone who has parental responsibility for the minor. Nevertheless such a refusal was a very important consideration in making clinical judgments and for parents and the court in deciding whether themselves to give consent." ${ }^{46}$

(iii) Incompetence: The involvement of mentally disordered people in research has been a subject of debate for long. Lord Brandon, in Re F (A Mental Patient: Sterilisation), ${ }^{47}$ [9] endorsed "best interests" tests for the treatment of mentally incompetent persons. However, in therapeutic and non-therapeutic research, it is extremely difficult to identify the person who can decide what is in the "best interests" of the subject. The safest route is, of course, to seek a court's declaration on the subject; however, the practice in Scotland is worth emulating, where a tutor dative can be appointed by the court on behalf of a mentally incompetent person, who shall enjoy the power, subject to the powers granted by the court decree, to consent on behalf of an adult to treatment [10-37].48

\section{Conclusion}

The certainty of law in the matters of medical ethics has been the clamour for the stakeholders since long. Informed consent forms one of the most pivotal legal requirements for conducting clinical trials involving humans. Not just the legislature, but the courts have also contributed a lot in the development of jurisprudence in this area. However, one school of thought still holds the view that there are difficulties in ascertaining an effective and coherent theoretical basis for the validity of consent in adults participating in clinical trials. Although not completely unfounded, yet this thought process is far removed from the facts. As we have seen from the above discussion, whatever loopholes exist, in the implementation of informed consent among humans used in research and experimentation, can be effectively plugged provided the necessary laws, rules and regulations are well drafted and enforced. The doctrine of informed consent requires disclosure about experimental treatments, and also patients and families can decide autonomously about them when the consent process is full and fair.

\section{References}

1. Bang v Charles T. Miller Hospital (1958) 251 Minn. 427, 88 N. W. 2d 186.

2. Vollmann J, Winau R (1996) Informed consent in human experimentation before the Nuremberg code. BMJ 313: 1445-1449. [Crossref]

3. Declaration of Helsinki (1964) World medical Association.

4. Mohr v Williams (1905) 95 Minn. 261, 104 N.W. 12.

5. Sidaway v Governors of Bethlem Royal Hospital (1985) AC 871.

6. Halushka v University of Saskatchewan (1965) 53 D.L.R. (2d) 436

7. Gillick v West Norfolk and Wisbech Area Health Authority (1985) 3 All ER 402.

8. Re W (1992) (Child in Care: Court's Jurisdiction) 3 W.L.R. 758.

9. Re F (A Mental Patient: Sterilisation) (1990) 2 AC 1.

10. Baker DW, Hayes R, Fortier JP (1998) Interpreter use and satisfaction with interpersonal aspects of care for Spanish-speaking patients. Med Care 36: 1461-1470. [Crossref]

11. Brock DW (2008) Philosophical Justifications of Informed Consent in Research. In The Oxford Textbook of Clinical Research Ethics pp. 606-612.

\section{${ }^{45}[1992] 3$ W.L.R. 758}

${ }^{46}$ Ibid.

${ }^{47}[1990] 2$ A.C. 1

${ }^{48}$ See Medical Research Council, The Ethical Conduct of Research on the Mentally Incapacitated, (MRC Ethics Series 1991). 
12. CIOMS (2016) International Ethical Guidelines for Biomedical Research Involving Human Subjects.

13. US. Department of Health and Human Services (1995) Protection of human subjects. Code Fed Regul Public Welfare Title 45: Unknown. [Crossref]

14. Dan Ariely (2012) The Honest Truth about Dishonesty: How We Lie to Everyone-Especially Ourselves

15. Emanuel EJ, Wendler D, Grady C (2000) What makes clinical research ethical? JAMA 283: 2701-2711. [Crossref]

16. Escobedo C, Guerrero J, Lujan G, Ramirez A, Serrano D (2007) Ethical Issues with Informed Consent, E-Zine Journal: Youth Scientists and the Ethics of Current Science Bio-Ethics Issue.

17. Evans D, Evans M (1996) A Decent Proposal: Ethical Review of Clinical Research, John Wiley and Sons p. 218

18. Friedman LM, Furberg CD, DeMets D, Fundamentals of Clinical Trials (4th Edn., Springer: 2010).

19. Jackson, J. (ed.) A Practical Guide to Medicine and the Law, Springer- Verlag, 1991.

20. Marshall P.A., "Cultural Competence" and Informed Consent in International Health Research, Cambridge Quarterly of Healthcare Ethics (2008), 17, 206-215.

21. McHale JV (1993) Guidelines for medical research -- some ethical and legal problems. Med Law Rev 1: 160-185. [Crossref]

22. MRC (1991) The Ethical Conduct of Research on the Mentally Incapacitated, Medical Research Council. MRC Ethics Series 1991.
23. Oppenheim M (1962) Informed Consent to Medical Treatment. Marshall L. Rev Clev 11: 249.

24. Official Regulations as to Tuberculin in Germany and Italy (1981) JAMA 16: 492

25. Piff P (2012) Higher Social Class Predicts Increased Unethical Behavior. Proc Natl Acad Sci USA 109: 4086

26. Pimentel Perez AG (2002) Los testigos de Jehova y el consentimiento informado. Revista de Medicina, Instituto Mexicano del Seguro Social (IMSS) 40: 495-504.

27. Pocock SJ (1983) Clinical Trials: A Practical Approach. John Wiley \& Sons p. 265.

28. Quittell RM (2001) Informed Consent and Human Experimentation: Present Status, Pitfalls, and the Need for Reform. Food and Drug Law.

29. Tobias JS, Souhami RL (1993) Fully informed consent can be needlessly cruel. BMJ 307: 1199-1201. [Crossref]

30. Humanium (1948) The Universal Declaration of Human Rights.

31. Wertheimer A (2014) (Why) should we require consent to participation in research? J Law Biosci 1: 137-182. [Crossref]

32. Luka v Lowrie (1912) 171 Mich. 122, 136 N.W. 1106.

33. McGuire v Rix (1929) 118 Neb. 434, 225 N.W. 120.

34. Natanson v Kline (1960) 186 Kan. 393, 350 P. 2d 1093.

35. Salgo v Stanford University (1957) 154 Cal. App. 2d 560, 317 P.2d 170.

36. Schloendorff v New York Hospital (1914) 211 N.Y. 125.

37. http://www.cioms.ch

Copyright: $\mathbb{C} 2018$ Arora P. This is an open-access article distributed under the terms of the Creative Commons Attribution License, which permits unrestricted use, distribution, and reproduction in any medium, provided the original author and source are credited. 